\title{
Affordability of healthy eating in Ireland in 2009 and 2014
}

\author{
M. C. Conway ${ }^{1}$, E. M. Keaveney ${ }^{1}$, A. W. Wicklow ${ }^{1}$, S. M. Ní Bhriain ${ }^{1,2}$, F. E. Douglas ${ }^{1}$, \\ A. T. Carr ${ }^{1}$ and M. A. T. Flynn ${ }^{1,2}$ \\ ${ }^{1}$ Public Health Nutrition, Food Safety Authority of Ireland, Dublin 1, Republic of Ireland and ${ }^{2}$ Northern Ireland Centre \\ for Food and Health, University of Ulster, Coleraine BT52 1SA, UK
}

Socio-economic disadvantage is associated with higher chronic disease risk ${ }^{(1)}$ emphasising the importance of affordability of healthy eating. This study evaluates the affordability of healthy eating for those dependent on social welfare in Ireland, in 2009 and 2014.

In 2009 , the four most typical households in Ireland ${ }^{(2)}$ and their social welfare allowance (SWA, including child benefit) entitlements ${ }^{(3)}$, were determined. SWA was calculated for the same households in $2014^{(4)}$. The weekly food requirements for healthy eating ${ }^{(5)}$ for each household were priced in three different grocery store outlets in 2014 and compared with similar data collected in 2009. Affordability of healthy eating was assessed as the proportion (\%) of SWA spent on food by each of the households in each of the outlets. This was also examined for the five food groups used in healthy eating guidelines for Ireland ${ }^{(5)}$.

\begin{tabular}{|c|c|c|c|c|c|c|}
\hline \multirow[b]{3}{*}{ Household } & \multirow{2}{*}{\multicolumn{2}{|c|}{$\frac{\text { Multiple Supermarket }}{\% \text { SWA }^{*}}$}} & \multirow{2}{*}{\multicolumn{2}{|c|}{$\frac{\text { Low Cost Outlet }}{\% \text { SWA }^{*}}$}} & \multirow{2}{*}{\multicolumn{2}{|c|}{$\frac{\text { Local Shop }}{\% \text { SWA }^{*}}$}} \\
\hline & & & & & & \\
\hline & 2009 & 2014 & 2009 & 2014 & 2009 & 2014 \\
\hline $1=$ Two adults with one teenager and one five year old child & 30 & 28 & 26 & 24 & 58 & 45 \\
\hline $2=$ Two adults without children & 26 & 25 & 21 & 21 & 49 & 36 \\
\hline $3=$ Elderly female adult & 15 & 13 & 13 & 11 & 25 & 22 \\
\hline $4=$ Single female adult with one five year old child & 22 & 21 & 18 & 17 & 43 & 31 \\
\hline
\end{tabular}

*\% SWA in this study is defined as the total cost of food required for healthy eating as a proportion of the households social welfare allowance (social welfare income, including child benefit, where relevant)

As shown in the summary table, healthy eating tended to be more affordable in 2014 compared with 2009, and was consistently least affordable in the Household with a teenager (Household 1). In 2014 compared with 2009, SWA decreased for Households 1, 2 and 4 , and food prices (for all Households) decreased significantly, in all outlets $(p<0.01)$. Overall, for all households, affordability for total food requirements improved significantly in the Multiple Supermarket $(p<0.05)$ and Local Shop $(p<0.001)$, and remained the same in the Low Cost Outlet. Affordability improved significantly for Household 1 in the Local Shop $(p<0.01)$. Affordability of foods in some food groups improved significantly, however this varied according to Household type and grocery store outlet.

In conclusion, although SWA decreased for three of the four households in 2014 compared with 2009, food prices also fell and therefore affordability has not been negatively affected. Food costs and affordability of healthy eating varies according to household and grocery store outlet and healthy eating remains least affordable for families with teenagers.

1. CSDH. (2008) Closing the gap in a generation: health equity through action on the social determinants of health. Final Report of the Commission on Social Determinants of Health. Geneva: World Health Organization.

2. Central Statistics Office (2006) Census 2006. Available from: http://www.cso.ie/ [Accessed May 2009].

3. Department of Social and Family Affairs (November 2008) Personal Communication.

4. Department of Social Protection (February 2014) Personal Communication.

5. Flynn MAT, O'Brien CM, Ross V et al. (2011) Revision of food-based dietary guidelines for Ireland, Phase 2: recommendations for healthy eating and affordability. Public Health Nutr 15(3), 527-537. 